\title{
La psicopatología como máscara de la existencia*
}

\section{Psychopathology as a M ask of Existence}

Recibido: septiembre 7 de 2007 | Revisado: mayo 16 de 2008 | A ceptado: mayo 29 de 2008

\section{G UILLERMO G ARCía** Alberto de CASTRO $0^{* * *}$}

U niversidad del N orte, Barranquilla, Colombia
Una modificación de este artículo será presentada como un capítulo del libro "Temas en psicología", volumen 2, Editado por la Especialización en Psicología C línica de la U niversidad del N orte y publicado por Ediciones U ninorte.

** Profesor del departamento de Psicología de la U niversidad del N orte, Barranquilla, Colombia. Correo electrónico: ggarcia@ uninorte.edu.co

${ }^{* * *}$ Profesor del departamento de Psicología y coordinador de postgrados de la División de H umanidades y Ciencias Sociales de la U niversidad del Norte, Barranquilla, Colombia.

Correo electrónico: amdecast@ uninorte.edu.co

\section{A B S T R A C T}

In this article, we present a theoretical reflection about the meaning of psychopathology in the context of human projects of life. This reflection is partially based upon the findings of four qualitative case studies about the understanding of the experience of anxiety. In this way, we clarify the existential foundations implicit in psychopathology, and we also perform an epistemological analysis on the way human beings could existentially approach psychopathology, in order to comprehend symptoms properly, bearing in mind some important concepts, such as intentionality and the meaning of the experience for the person who is living the psychopathological symptoms.

Key words authors

Psychopathology, existential psychology, comprehension, meaning and intentionality.

Key words plus

Psychology, Pathological, Existential Psychology.

\section{R ESU M E N}

En este artículo se presenta una reflexión teórica acerca de lo que significa la psicopatología en el contexto del proyecto de vida de los seres humanos. Dicha reflexión se basa parcialmente en los resultados de cuatro estudios cualitativos de caso realizados desde una perspectiva fenomenológicahermenéutica sobre la comprensión de la experiencia de ansiedad. En este sentido, se clarifican los fundamentos existenciales implícitos en la psicopatología y se hace un análisis epistemológico acerca de la forma en que podemos aproximarnos existencialmente a la psicopatología para poder comprender apropiadamente los síntomas, teniendo presente conceptos como intencionalidad y sentido de la experiencia de la persona que está vivenciando los síntomas psicopatológicos.

\section{Palabras clave autores}

Psicopatología, psicología existencial, comprensión, sentido e intencionalidad.

Palabras clave descriptores

Psicopatología, psicología existencial. 
Es muy común encontrar en la ciencia en general, que cuando alguien se refiere a algún tipo de investigación, a partir del modelo basado primordialmente en análisis estadísticos, el esfuerzo siempre se encamina a "detallar" la situación de la(s) persona(s) que está(n) siendo objeto de estudio en términos lo más claro y evidente posibles. Pues bien, si bien escierto que estos aspectos son extremadamente importantes para que sean estudiados y tratados objetiva y detalladamente, también es igualmente cierto quetodas las anteriores son creadas por alguien especifico en alguna situación específica. Y cuando hablamos de "alguien específico" no nos referimos tanto a detalles de la población estudiada (sujetos, edad, sexo, nivel socioeconómico, nivel educativo, etc.), sino más bien a la experiencia de ese alguien que precisamente está creando dichas características de personalidad, estrategias de pensamiento, mecanismos defensivos o respuestas psicofisiológicas, conductuales 0 emocionales, enfatizando en aquello que la persona busca o pretende lograr para sí mismo al crear alguno de los anteriores y en cómo se experiencia a sí mismo en dicha creación.

Basado en lo anterior, el punto central al quenos referiremos en el presente estudio es a la necesidad de dejar de lado la lucha "ciega" y cortante entre la tendencia puramente objetiva u objetivista ( propia del modelo médico) y la puramente subjetiva o subjetivista ( propia de al gunas escuelas y/o disciplinas de las Ciencias Sociales que reaccionan contra el modelo médico), para que ubiquemosy contextualizemos cualquier objeto de estudio (tales como un mecanismo, impulso o dinamismo psicológico) en la situación concreta en que es creado y experienciado por ese alguien que lo está haciendo.

Precisamente, $M$ ay denomina a esta dicotomía sujeto-objeto la "zona cancerosa" donde se pierde a sí misma la ciencia. De ahí que Binswanger sostenga que la relación entre la experiencia subjetiva y los conceptos objetivos tienen un punto de encuentro en la existencia concreta del ser humano. Ferro Bayona (2001) comenta al respecto:

la concordancia no es posible si no se hace sobre el fondo de una nueva explicación, que no tome al hombre como objeto sino como existencia, a saber, que el hombre es ser-en-el-mundo, que está con, que es lo que constituye el espacio donde se mueve la situación analítica. (p. 52)

La idea, según esto, no es negar la validez y la preocupación por la técnica, la objetividad y las distintas consideraciones teóricas acerca del ser humano, sino captar que según la psicología existencial, los mecanismos y estructuras teóricas acerca del ser humano sólo tendrán sentido cuando se hable de ellas en función de la persona existente. Esto es encontrado en diversos estudios cualitativos de caso con entrevistas en profundidad realizados con orientación fenomenológica hermenéutica (D e Castro, 2005a, 2005b; De Castro \& Salamanca, 2007; De Castro, Cardona, Támara $\&$ Gordillo, 2007).

Esasí como el enfoque existencial en psicología plantea que antes que contraponer las tendencias y actitudes orientadas a la objetividad y la subjetividad y pretender elegir sólo por una de ellas, debemos darnos cuenta de que son aspectos de la misma realidad pero que funcionan en niveles distintos de experiencia (y el error consiste en confundirlos y negar alguno de ellos). M ediante la primera, se pretende explicar al ser humano aportando valiosas consideraciones técnicas y de diagnóstico y mediante la segunda, lo que se busca es comprenderlo a partir de su relación y situación en el mundo. De ahí, que se haga indispensable relacionar los comportamientos, ideas, emociones y actitudes de las personas con el contexto (no sólo histórico, social y cultural, sino también psicológico) en el que se crean o desarrollan todas ellas (H alling \& Goldfarb, 1996).

A sí, será imposible comprender a cualquier persona viva si no se piensa a ésta misma a partir de la existencia concreta - dicho en palabras de Jaspers- y no a partir de una generalidad abstracta, tal como afirma M ay (1963, p. 17): "Cuanto más se formulen las fuerzas y los impulsos de manera absoluta y completa, tanto más se estará hablando de abstracciones y no del ser humano existente". Y el punto central con lo aquí expuesto, es que la comprensión debe preceder a toda explicación, 
dado que se busca comprender primeramente la forma en que el individuo ha estructurado su mundo, para, a partir de ahí, arrojar la explicación pertinente y según la perspectiva existencial aunque hay un sólo mundo objetivo con el que interactuamos, en últimas, cada ser humano crea y constituye su propio mundo a partir de cómo se experiencie a sí mismo en su relación con éste. A tendiendo a esta idea $\mathrm{M}$ ay, $\mathrm{A}$ ngel \& Ellenberger (1977) proponen que:

El mundo es la estructura de relaciones significativas en que existe una persona y en cuya configuración toma parte. A sí, el mundo abarca los sucesos del pasado que condicionan mi existencia y toda la inmensa variedad de influencias determinantes que actúan sobre mí. Pero en tanto abarca todos estos elementos en cuanto me relaciono con ellos, tengo conciencia de ellos, los llevo conmigo, moldeándolos, formándolos, construyéndolos inevitablemente cada vez que me pongo en contacto con ellos. Pues el tener conciencia del mundo significa al mismo tiempo estarlo estructurando. (p. 85)

Según lo anterior, M erleau Ponty (1962) afirma que el mundo no es una realidad externa que existe por sí sola y a la cual se puede contemplar y percibir "desde afuera". En consecuencia, debemos atender al ser humano como alguien constructor y capaz de constituir su propio mundo y el sentido del mismo (Boss, 1979, 1982, 2001; Pollio, H enley \& Thompson, 1997). Esto no es más que atender a éste como ser-en-el-mundo, tal como planteó Heidegger, según lo cual, el hombre manifiesta cierto cuidado por los elementos concretos del mundo objetivo para formar y darle vida a sus proyectos y acciones. Un claro ejemplo de esto lo ofrece Estanislao Zuleta en una conferencia titulada "A la memoria de Heidegger" (pronunciada en Junio de 1976 en la U niversidad del Valle, Cali, Colombia), cuando nos muestra como aunque a una silla le puede faltar una pata o un brazo, eso es sólo un hecho significativo para nosotros, los seres humanos, ya que para la silla por sí sola, como naturaleza física que hace parte del mundo, nada le es carente. La silla es lo que es sólo a partir de nuestra relación con ella, de su utilidad y función para nuestras acciones y proyectos en el mundo. Esto se entiende aún mejor si atendemos la siguiente afirmación de Binswanger (1977, pp. 238-239) sobre esto mismo: "cuando hablamos de mundo en términos de A nálisis Existencial, significa por mucho, aquello hacia donde ha saltado la existencia humana y conforme a lo cual se ha proyectado ésta (...), mundo no significa solamente la formación del mundo o su plano trazado de antemano, sino también la forma de ser-en-el-mundo y la actitud hacia el mundo".

D e esta forma, es pertinente aclarar que si bien es apropiado preguntarse por variables implicadas en los procesos psicológicos cotidianos de los seres humanos (estructuras psicológicas, mecanismos de enfrentamiento, emociones, etc.), es muy importante, tal como sugiere Bugental (1964, 1987, 1997), interrogarse acerca del sentido de la experiencia y la intencionalidad de la persona concreta que está creando sus propias emociones y mecanismosa partir de su vivencia como ser-en-el-mundo. Se trata de interrogarse en primera instancia acerca de la persona concreta y lo qué preten de reafirmar y construir en su experiencia en el mundo. D e ahí, que sólo desde el conocimiento de la situación existencial propia de cada quien, se debería construir cualquier interpretación teórica. En este sentido, Van den Berg (1997) sugiere que los psicólogos deberían tratar de responderse cuestionamientos como: ¿Cuál es la relación de la persona y los objetos del mundo? ¿Cuál es la relación de la persona con su propio cuerpo? ¿C uál es la relación de la persona con otros individuos? 0 ¿cuál es la relación de la persona con el tiempo en general, lo cual implica tanto el pasado como el futuro? Y en caso de que se presente una psicopatología, preguntarse además, como son todas estas relaciones cuando existe un disturbio mental.

En otras palabras, tenemos que preocuparnos en primera instancia por descubrir el centro existencial de la persona y los valores concretos y particulares en que esté centrado. Dicho en palabras de M ay (1963, p. 17): "la cuestión de por quéuno es lo que es, no tiene sentido hasta saber qué es uno". 
Esto quiere decir que antes que desarrollar cualquier técnica, diagnóstico o construcción teórica acerca de alguien (lo cual funciona en el nivel de la explicación, en la búsqueda del por qué), se debe comprender el significado de los comportamientos, ideas, impulsos y sentimientos para la persona que los está creando y experienciando (lo cual opera en el nivel de la comprensión, en la búsqueda del qué). Por consiguiente, se trata de aplicar cualquier porque a la situación concreta de la persona, haciendo que "la técnica tenga sentido en función de la persona y no al contrario", tal como sugiere el mismo M ay (1963, p. 17).

A hora bien, podremos apreciar que en los datos alrededor de los cuales se encuadran las descripciones que ofrece el DSM IV para diagnosticar las distintas enfermedades mentales, en todo momento se hace estricta aunque detallada referencia a los criterios y características para el diagnóstico, a los síntomas que sufre el individuo, a la forma como estos evolucionan durante la enfermedad, a las estadísticas en cuanto al pronóstico y la prevalencia de la misma, a los subtipos y trastornos asociados, y a los criterios para hacer un diagnóstico diferencial.

Y si bien es cierto, como hemos dicho, que es supremamente importante tener absoluta claridad sobre estos aspectos para quien trabajela psicología clínica, también es muy importante recalcar que mientras la descripción (y aun, la explicación) de la enfermedad mental sólo se dé a partir de criterios estadísticos, se generaliza la experiencia humana hasta tal punto que se crea una brecha tanto del paciente con sus propios estados psíquicos y entre estos últimos y el mundo en que se encuentra, así como de la persona enferma y aquel que busca comprenderlo, debido a que de esta forma sólo se separa la experiencia de ambos en "patológico" y "sano", limitando la visión que cada uno de ellos pueda tener del otro. En este sentido, $M$ ay et al. (1977, p. 46) afirman: "la cuestión fundamental es averiguar como reacciona un paciente a una experiencia, y no si de hecho es verdadera o falsa".

Si no se contextualizan la observaciones acerca de alguien a partir del sentido de su experiencia, como consecuencia el observador "sano" sólo bus- cará en el enfermo las desviaciones en cuanto a su conducta, emociones y pensamientos con referencia a la forma en que él (el observador) las concibe para así poderlas diagnosticar, con el agravante de que de esta forma no capta aquello que la persona enferma pretende ser con su enfermedad, debido a que en aras de una supuesta neutralidad, se ha apartado de la experiencia de dicha persona. Según D reyfus (1996, p. 51), cuando así actuamos, estamos dando un paso atrás en nuestra comprensión del otro "y nos convertimos en observadores reflexivos y desapegados, y no nos queda más remedio que vernos como sujetos contemplando objetos". De ahí, que sea necesario que siempre estemos pendientes y atentos a clarificar nuestras propias ideas preconcebidas, prejuicios, reacciones 0 asunciones acerca de la problemática que estamos atendiendo y al tiempo que evitamos así crear barreras o desviaciones en el entendimiento del otro, purificamos nuestras interpretaciones acerca de la persona (H alling \& Goldfarg, 1996). D e no hacer esto, perdemos la captación del otro como ser-en-el-mundo y dejamos de compren der la totalidad de su experiencia. Y según Binswanger la única forma como podemos informarnos acerca de alguien es mediante la captación de la concepción que éste tenga del mundo, de forma tal que nos guíe en el conocimiento de su estructura. De ahí que este autor (1977, p. 237) afirme arraigado en la fenomenología que "en vez de proyectar nuestras ideas sobre las cosas, debemos dejar que las cosas hablen por sí".

Si no procuramos comprender al ser humano, se podrá captar, como dice $M$ ay, todos los detalles y aspectos teóricos relacionados con la persona observada, pero desligados de la experiencia de la persona misma y de su relación y situación en el mundo, lo cual lleva a no comprender el sentido de la enfermedad mental y sus síntomas patológicos. Y lo que mediante esta actitud no se alcanza a percibir es que el ser humano no tiene una enfermedad en sí, sino que él mismo es la enfermedad, en el sentido de que todos sus síntomas patológicos son creados a partir de la estructura existencial que él mismo ha creado con un fin particular. La enfermedad mental no concierne en primera instancia a 
sus propios síntomas, sino más bien a la estructura en que se apoyan dichos síntomas y esta estructura es netamente de carácter existencial debido a que se construye a partir de la relación de la persona con el mundo, los otros y consigo mismo, es decir, a partir de su vivencia de ser-en-el-mundo.

Dicho de otra forma, para comprender la enfermedad mental, primero (y sobre todo!) se debe captar y esclarecer la estructura de la existencia del otro en cuanto ser-en-el-mundo, lo cual implica atender, según Binswanger (1977, p. 243), "a las formas en que diseña y construye el mundo (el proyecto y la imagen que se forma del mundo); sus correspondientes estilos de ser como persona (esto es, las formas en que se afirma o no se afirma a sí mismo); y las formas de trascendencia en cuanto tal, es decir, la actitud que toma la existencia en el mundo (su actuar, pensar, crear, imaginar, etc.). A sí, el análisis existencial se propone examinar y describir la forma en que conciben el mundo, afirman su yo y actúan y aman los diferentes tipos de enfermos mentales en general y cada paciente en particular y por sí mismo".

Esto significa que sólo al captar y comprender el qué de la estructura de la existencia del otro y de su proyecto vital en el mundo, tendremos información suficiente y real referente a las causas (por qué) y a los mecanismos y medios de que se vale la persona (cómo) para poder explicar tanto su existencia como sus distintos síntomas patológicos, debido a que de esta manera estaremos atendiendo al contenido concreto de su mundo, de su proyecto y de su experiencia en el mundo, que es lo que en últimas se busca revelar. De ahí, que lo que se observa directamente son los síntomas de la enfermedad mental, pero ésta última sólo se puede comprender, lo cual se entiende mejor si atendemos al hecho de que en un principio, debemos preocuparnos por obtener tanta información como sea posible sobre la experiencia del paciente desde su propia perspectiva (Blankenburg, 1980), sin ser demasiado selectivo en cuanto a no enjuiciar teóricamente (repetimos, en un principio al menos) dicha experiencia.

En este sentido, podemos comprender entonces que los distintos aspectos que nos ofrece el
DSM IV sobre la enfermedad mental, se refieren exclusivamente a dar claridad sobre todo aquello concerniente a las los síntomas de la enfermedad, a cómo se dan y evolucionan y a las distintas pautas para realizar un diagnóstico con base en ellos, pero nos esclarece la base o estructura de existencia sobre la que dichos síntomas y enfermedades se construyen $y$, por consiguiente, tampoco nos da claridad sobre cómo comprender el significado de la enfermedad mental para quien la está viviendo. De ahí, que el DSM IV por sí sólo, divorciado de la experiencia concreta y contexto psicológico en que se presentan los distintos síntomas, llevará al psicólogo a tener una mirada unidireccional desde su propia perspectiva (H alling \& Goldfarg, 1996), ignorando el significado de la experiencia del otro y oscureciendo así la comprensión de su enfermedad. Esto sólo llevará al psicólogo a juzgar teóricamente la experiencia del otro, antes que comprenderla, ya que sólo pretenderá validar o rechazar las conductas del otro de acuerdo a su concepción previa acerca de la enfermedad. En este sentido, Fischer (1986) comenta que el entendimiento general que el psicólogo tenga sobre la existencia humana, preconfigurará su entendimiento acerca de la psicopatología, lo cual, a su vez, lleva a tener una visión exclusiva de la psicopatología ( $M$ alone, 1995), ya que se excluyen otros posibles significados de la enfermedad distintos a aquel que ya ha sido preconfigurado por el psicólogo antes de tener contacto con la experiencia directa e inmediata del paciente.

Para ofrecer una clara muestra de esto, tomaremos del M anual de Diagnóstico y Estadístico de los Trastornos M entales DSM IV algunos casos representativos: el trastorno obsesivo compulsivo y la fobia específica, de los cuales, vale aclarar, tomamos solamente los datos más relevantes de cada uno de ellos referentesa la definición del trastorno psicopatológico, pretendiendo no reducirlosa estos pocos detalles, sino enten diendo que lo que ofrece el manual gira entorno a dichos datos para realizar el diagnóstico:

- Trastorno O bsesivo-compulsivo (DSM IV, pp. $428-429)$ : 
- Presencia de obsesiones o compulsiones de carácter recurrente lo suficientemente graves como para provocar pérdidas de tiempo significantes.

- Las obsesiones se definen como ideas, pensamientos, impulsos o imágenes de carácter persistente que el individuo considera intrusas e inapropiadas y que provocan una ansiedad o malestar significativo. Esta cualidad intrusa e inapropiada que caracteriza las obsesiones se ha venido a denominar egodistónica (sensación de que la obsesión es ajena al propio control y no encaja en el tipo de pensamientos que esperaría tener).

- El individuo que tiene obsesiones intenta con frecuencia ignorar o suprimir estos pensamientoso bien neutralizarlos mediante otras ideas 0 actividades denominadas compulsiones (comportamientos 0 actos mentales de carácter recurrente cuyo propósito es prevenir 0 aliviar la ansiedad o el malestar).

Si miramos entonces, detenidamente la forma en que se define el trastorno obsesivo compulsivo, notaremos que se refiere a que en éste hay presencia de obsesiones (ideas o pensamientos de carácter persistente que el individuo considera intrusos e inapropiados y que provocan ansiedad), pero en ningún momento nos advierte o muestra el sentido de tener que crear un pensamiento 0 imagen obsesiva y/o tener que recurrir a un acto compulsivo para la reafirmación de la persona como tal. En este punto, se hace pertinente traer el diálogo entre el terapeuta y paciente que Yalom crea en su libro EI día que N ietzsche lloró (1995, p. 212), cuando el terapeuta le dice al paciente: "U sted ha hablado mucho acerca del "asalto de pensamientos extraños". A hora comprendo cómo se apoderan de su mente esos pensamientos extraños. N o obstante, son sus sentimientos y es su mente. M e pregunto qué beneficio obtiene usted al permitir que esto ocurra o (por decirlo con más fuerza) al hacer que ocurra".

El manual dice que las obsesiones "provocan" ansiedad y las compulsiones "buscan" aliviarla.
Lo cierto del caso es que en sí, quien siente, crea y busca aliviar la ansiedad es la persona y no el mecanismo que emplea; de ahí que nos debamos preguntar por el fin o propósito de la persona por evitar la ansiedad: ¿ansiedad de qué y ante qué? ¿qué valores está sintiendo esta persona que se están viendo amenazados en su existencia concreta? ¿qué valoresnecesita esta persona afirmar o preservar para sentirse alguien con al gún sentido? ¿cómo pretende esta persona concreta afirmarse, preservarse 0 defenderse y con qué fin (intencionalidad)? ¿qué obtiene afectiva o emocionalmente esta persona al afirmarse, defen derse o preservarse de la manera particular en que lo está haciendo? Todas estas preguntas nos llevan a interrogar el sentido e intencionalidad de la experiencia de la persona antes que el mecanismo compulsivo ( como si fuera independiente de la persona que lo está creando), ya que éste último es en este caso, sólo el medio por el que el proyecto de la persona se manifiesta.

Cuando anteponemos preguntas teóricas orientadas a los mecanismos, impulsos o dinamismos sin ubicarlos y contextualizarlos desde la vivencia, sentido e intencionalidad de la experiencia de la persona que está vivenciando dichos mecanismos, impulsos o dinamismos, se le está dando un poder por sí mismo a las obsesiones y a las compulsiones, tornando la mirada en el otro como un objeto, ya que no se atiende a él como persona sino sólo a las distintas partes (mecanismos, dinamismoso impulsos tales como las compulsiones) desarticuladas y separadas de la totalidad de la existencia de dicha persona, siendo que en realidad éstas son operadas y creadas por alguien sobre la base de una estructura de existencia, que según M ay et al. (1977, p. 222), "se conserva potencialmente intacta pero que se encuentra condenada a la impotencia de afirmarse a sí misma".

Entonces, quien opera únicamente con base en el DSM IV (nótese que decimos únicamente, con lo cual nos referimos tanto a centrarse sólo en el diagnóstico sin tener presente dicha estructura de la existencia, como a no irse al polo opuesto y rechazar totalmente lo planteado por éste), podrá hablar de los síntomas de la persona obsesivo com- 
pulsiva, sin estar hablando de esa misma persona, es decir, de aquello que pretende lograr, preservar u obtener con dicha enfermedad, al tiempo que omite el proyecto vital de dicha persona que se ha visto frustrado $y$, debido a lo cual, no ha podido ni reafirmarse auténticamente ni proyectarse constructivamente hacia un futuro. Esta idea es desarrollada aún más por M ay et al. (1977) cuando comenta:

La vida sana apunta al futuro, va soltando constantemente el pasado, dejándolo atrás, limpiándose de él. Pero no así el compulsivo, éste no toma el pasado como un tiempo pretérito, así no puede eliminarlo ni dejarlo atrás, pues esto le exigiría la apertura hacia el futuro (...) no sólo no avanza en sus posiciones, sino que se ve invadido por el pasado a través de los símbolos de impuro, manchado y muerto. Se trata de una deformación enemiga de la vida que es la forma del perenne devenir: es una deformación en la que se atrinchera el pasado, también deformándolo. (p. 221)

El obsesivo compulsivo, según la psicología existencial, es alguien que lucha con las potencias que podrían destruir su existencia, que a la larga termina sien do un esfuerzo estéril, dado que dichas fuerzas ya se han apoderado de él mismo bajo el patrón obsesivo compulsivo de comportamiento. Dado que no ha podido reafirmarse a sí mismo auténticamente en el mundo, su esfuerzo se encamina entonces a tratar de evitar la sensación de sentirse impotente y de ahí que perciba al mundo como amenazante, lo cual se expresa en imágenes de impureza, desorden, suciedad y excremento entre otros. Von Gebsattel (1977, p. 230) afirma al respecto: "esta orientación compulsiva del proceso fundamental de su vida no le induce a expansionarse, desenvolverse e intensificar su autorrealización, sino a restringir, rebajar y disolver el impulso vital, y así hace al compulsivo vulnerablea todas las acometidas de las potencias destructoras de la vitalidad, proyectadas en objetos como los excrementos, la muerte, la bestialidad infecciosa, el veneno, el fuego, etc.".
En últimas, la preocupación del obsesivo compulsivo es sobre su capacidad y posibilidad de ser y de la sensación de amenaza que experimenta; por eso recurre a un proyecto secundario (el comportamiento obsesivo compulsivo en sí) para adquirir seguridad ante dicha sensación de amenaza y obtener el control, orden y/o limpieza que siempre ha deseado.

En la medida en que el obsesivo compulsivo pueda comenzar a reafirmarse constructivamente, comenzará a proyectarse hacia el futuro y en ese momento podrá desarrollar su propia estructura de potencialidades que se hallaba intacta precisamente por no haberse sentido capaz de reafirmarla; sólo de esta forma comenzará a superar su sintomatología.

Pero aquí hay un inconveniente bastante difícil de superar que es precisamente lo que le impide al obsesivo compulsivo reafirmarse a sí mismo y es el hecho que el hacer esto implica responsabilizarse de su propia creación como persona, libre de seguridades inmediatas que le impiden realizar su proyecto a largo plazo, tal como comenta Yalom (1984, p. 274): “U na delas defensas dinámicas más comunes contra la conciencia de la responsabilidad es la creación de un mundo psíquico en el cual no se experimenta libertad, sino que se vive bajo el imperio de una fuerza irresistible que es ajena al yo ('no yo'). A esta defensa la conocemos con el nombre de 'compulsividad'".

El punto a tener en cuenta es, entonces, que si no se atiende a quien se está afirmando mediante un patrón obsesivo compulsivo de comportamiento, como aquel que se vale de la enfermedad para mantenerse a distancia de sí mismo (para no querer afirmarse constructivamente), no se captará el significado de su proyecto y su orientación en el mundo y no se podrá, por consiguiente, hacer que experimente su existencia como real, cosa que ocurrirá si sólo se atien de a la persona obsesivo compulsiva como un objeto que tiene ciertos síntomas.

Fobia Especifica (antes: fobia simple) (DSM IV, pp. 414 - 415):

- La característica esencial de la fobia es un miedo intenso y persistente a objetos o situa- 
ciones claramente discernibles y circunscritas. La exposición al estímulo fóbico provoca casi invariablemente una respuesta inmediata de ansiedad (la cual puede adquirir la forma de una crisis de angustia situacional) .

- El diagnóstico es correcto sólo si este comportamiento de evitación, miedo 0 ansiedad de anticipación en relación con el estimulo fóbico interfiere significativamente con las actividades cotidianas del individuo.

- El individuo experimenta un temor marcado, persistente y excesivo o irracional cuando se encuentra en presencia de objetos o situaciones específicas o bien cuando anticipa su aparición.

EI DSM IV define la fobia específica con base en el miedo persistente a objetos o situaciones especificas y a que la exposición a dicho objeto o situación provoca una respuesta intensa de ansiedad de forma tal, que interfiere con su cotidianidad. I gualmente, como ocurrió al abordar el trastorno obsesivo compulsivo, tampoco se muestra aquí la importancia de investigar los proyectos u orientaciones de la persona en el mundo, que hicieron posible la aparición de los síntomas fóbicos.

Según la psicología existencial, el temor especificado en un objeto propio de la fobia, en últimas, enmascara un temor más fundamental como es el temor a la muerte, entendiendo por esto el miedo y rechazo de la sensación de amenaza de la propia existencia y/o al proyecto que se pretende crear, en otras palabras, a la experiencia de no ser. ¿Q ué es en últimas aquello que teme el fóbico ante el objeto en el que ha proyectado sus temores? ¿Q ué es sino la muerte lo que se teme al sentir que se asfixia en un ascensor 0 al sentir que se ahoga porque no al canza el fondo de la piscina 0 al sentir que será alcanzado y mordido por una rata? A nte esto, el individuo pretenderá preservar la total estructura de su existencia a costa de sí mismo, ya que evita confrontarse a sí mismo y sus temores más profundos en aras de una seguridad que es sólo aparente. Binswanger (1977, p. 251) hace referencia a esto cuando afirma que " $L a$ fobia representa siempre un intento por salvaguardar un mundo restringido y empobrecido".
D e esta forma, la fobia se convierte en un mecanismo o instrumento para mantenerse al margen de la experiencia de desaparecer del mundo 0 de fracasar en el intento de crearse a sí mismo. Dicho en palabras de Binswanger (1977, p. 255): "representa una protección de la existencia contra la invasión de algo inconcebiblemente espantoso" y esto no es más que sentir la amenaza de la propia experiencia de morir.

A sí, no se debería tanto tratar de aliviar la ansiedad ante el objeto de su fobia, sino más bien confrontar a la persona con la fuente de dicha ansiedad: la experiencia de no ser o de muerte - donde precisamente se enraíza el trastorno fóbico- (entendida en un sentido tanto físico como psicológico, en el cual lo que se teme es el fracaso o cese de un proyecto de vida y/o la imposibilidad de seguir afirmando o preservando valores que le otorgan al individuo algún tipo de sentido). Sólo al asumir constructivamente esta experiencia, el individuo podrá asumir por sí mismo la orientación libre de su proyecto vital y superar así los síntomas fóbicos.

Según lo visto en los dos ejemplos anteriores, debemos dejar en claro, entonces, que la enfermedad no tiene que verse, por lo menos en primera instancia, como contraria a la salud, hablando puntualmente en cuanto a su forma de operar (ya que de ambas formas se busca reafirmar algo de sí mismo, preservar algún valor que otorgue sentido a la experiencia presente) y no en cuanto a sus aspectos cuantitativos (salud mental: ausencia de síntomas, enfermedad: presencia de síntomas). Dorr (1996, p. 484) comenta que "los fenómenos psicopatológicosno deberán ser vistos como meras deficiencias con respecto a una normalidad término medio. M ásfecundo parece el punto de partida de buscar la 'positividad de lo negativo' ".

A sí, la enfermedad mental es vista según la psicología existencial como el resultado de la desviación de la persona de su propia estructura de potencialidades para desarrollar su proyecto vital coherentemente (y no como resultado de la desviación de mis criterios teóricos de normalidad), viendo así que al frustrarse éste último, se trata desesperadamente de recurrir a algún medio (enfer- 
mizo) para tratar de preservarse a sí mismo. Según Binswanger (1988, p. 199), la enfermedad mental a nivel general, se presenta cuando en alguna medida hay "frustración de la existencia humana, y llevando esto hasta el plano más universal, una frustración entendida como una forma de permanecer detenida la auténtica movilidad histórica de la existencia o de su arribar-a-un-final".

Según lo anteriormente expuesto, la persona enferma mentalmente, al ver frustrado el proyecto de su existencia, se esfuerza en reafirmar su enfermedad como forma de preservar su propio centro existencial. Es decir, que ante la frustración y parálisis de su proyecto y sentido vital, la persona recurre a algún otro proyecto, que aunque restringidamente, le permita sentirse no obstante como alguien con algún valor, a la vez que mantiene alejado con éste último, aquello que lo hace sentirse amenazado. Esta idea es expuesta por distintos psicólogos existencialescomo M ay (1990a) cuando afirma que los síntomas de una persona se refieren a la forma particular de elegir el campo (limitesposibilidades) de su mundo de forma tal que su centro de valoración y su sentido personal puedan ser protegidos de las amenazas, o por Laing (1974, p. 201) al comentar: "si el individuo no puede dar su realidad, vivencia, autonomía e identidad propia y la de los demás por descontadas, entonces habrá deabsorberse en encontrar maneras detratar de ser real, de mantenerse a sí mismo y a los demás vivos, de conservar su identidad, en esfuerzos, según lo formulará a menudo, para evitar perder su yo".

U n claro ejemplo de esto lo ofrece Erich Fromm (1992, caps. I, II y V) en el libro M iedo a la libertad, cuando comenta que el ser humano desde niño, debe ir cortando los vínculos primarios con su madre para "arrojarse" a enfrentar el mundo por sí mismo, buscando y obteniendo libertad e independencia. Pero en la medida en que esto es bloqueado por alguna razón especifica, el niño dejará de buscar su libertad y se mantendrá apegado a dichos vínculos primarios para obtener seguridad (Smith \& Jones, 1993), dado que por sí mismo se ve impedido e impotente para enfrentar el mundo, al que percibe en consecuencia en forma abrumadora y amenazante.
Pues bien, esta persona que no ha obtenido su libertad psicológica, recurrirá a mecanismos evasivos respecto a su propia voluntad y responsabilidad para evitar la sensación de amenaza proveniente del riesgo y compromiso que exigen estas últimas, dado que el ser libre implica verse sólo a sí mismo y por sí mismo enfrentan do el mundo, cosa que no se permiteal sentirse impotente (Yalom, 1984, 2000, 2002). A sí, la persona puede llegar a sufrir y hasta quejarse por sentirse incapaz, vacío, inconforme, insatisfecho, insignificante, frustrado, impotente, no tenido en cuenta por otros, etc., cuando al mismo tiempo, su intencionalidad muestra que en últimas, lo que realmente pretende es sentirse así precisamente (a pesar de que vivenciarse de esta manera implique sufrir), ya que cuando se siente de esta manera se victimiza a sí mismo y se impide enfrentar constructivamente cualquier experiencia, lo cual le permite sentirse seguro en algún grado. Esta experiencia implica una renuncia a desarrollar el propio potencial de ser que es a lo que $M$ ay se refiere cuando afirma que los seres humanos pueden preferir u optar por restringir sus posibilidades de acción con tal de no correr riesgos en la vida cotidiana, sin importar cuán dolorosa o frustrante puede resultar esta experiencia.

A hora bien, al tiempo que el individuo evita asumir su libertad, pretende darse al gún valor como persona al tratar de al guna forma de autoafirmarse destructiva o violentamente (Diamond, 1996) , 0 al tratar de darse un sentido, que según el mismo Fromm $(1992,1994)$, puede ser mediante medios conformistas, destructivos o referentes al autoritarismo, para por medio de ellos sentirse alguien (con poder y significación), lo cual compensa en alguna medida sus sentimientos de impotencia e insignificancia, no importando que el valor que crean aquí restrinja el desarrollo de su auténtica potencialidad como seres humanos.

Esta concepción de la enfermedad mental está altamente basada en la visión e importancia que para los psicólogos existenciales tiene la libertad en la vida cotidiana de las personas, lo cual se refleja puntualmente en la forma cómo se confronta la experiencia de ansiedad. Sin embargo, antes de entrar a detallar cómo se confronta la ansiedad, 
es necesario clarificar que la experiencia de ansiedad es un aspecto fundamental dado a todo ser humano, lo cual es sustentado por diversos autores (Spinelli, 2000; M ay et al., 1977; De Carvalho, 1992), así como es algo encontrado en diversasinvestigaciones sobre la experiencia de ansiedad ( $D$ e Castro, 2005a, 2005b; De Castro \& Salamanca, 2007a; D e Castro, Cardona, T ámara \& Gordillo, 2007b). En sí misma, la ansiedad no necesita ser vista en un principio como una experiencia contraria a la salud mental, sino como una experiencia siempre presente en la existencia humana debido a que está implicada en las decisiones y proyectos de nuestra vida cotidiana, lo cual la hace ser una experiencia que todo ser humano debe confrontar. Con base en esto, podemos entender de mejor forma la definición de la ansiedad elaborada por $M$ ay (1963, p. 35): "La ansiedad es la reacción básica de los seres humanos hacia un peligro sobre su existencia, o hacia algún valor que el/ella identifique con su existencia." Entonces, dado que la ansiedad es una experiencia presente en todo momento, antes que un síntoma patológico en sí, la forma como ésta va a ser vivenciada depende directamente de la forma como es asumida, confrontada e integrada a la existencia misma por medio de la conciencia. A I respecto, Riemann (1996) afirma que cada persona cuenta con una forma concreta, peculiar e individual de vivenciar la ansiedad y en esta forma de asumir la ansiedad, se reflejan tanto las limitaciones como las posibilidades que el ser humano concibe, percibe y desde las cuales orienta sus decisiones cotidianas. A sí, la ansiedad, dice Riemann (p. 11), "presenta una doble faceta: puede, por una parte, volvernos activos; por otra, puede paralizarnos. La ansiedad es una señal de alarma ante los peligros; implica, al mismo tiempo, un rasgo de exigencia: el impulso a superarla".

Como resultado, si somos capaces de confrontar la ansiedad constructivamente, en gran parte, estaremos estableciendo firmemente una estructura psicológica sobre la cual y a partir de la que podamos ser capaces de alcanzar en algún grado un estado y/o modo de ser saludable. Si no somos capaces de afrontar la experiencia de ansiedad constructivamente, degenerará en estados alta- mente patológicos. A I respecto, Yalom (1984, p. 251) comenta sobre la ansiedad: "Todos los seres humanos la sufren, pero en algunos es tan exacerbada, que se extiende a muchos otros terrenos de la experiencia y provoca un aumento de la disforia y/0 una serie de defensas frente a la misma que constriñen el desarrollo, originando a continuación la aparición de una angustia secundaria". Esta misma idea es expresada por D orr (1995, p. 350) cuando afirma que la "conducta anormal aparece como substituto de otras conductas más elaboradas que por alguna razón han sido reprimidas y/o no han alcanzado el desarrollo necesario".

D esde una perspectiva existencial, psicológicamente hablando, la experiencia de ansiedad está muy relacionada con el futuro y la incertidumbre implicada en éste (Keen, 1970; Fischer, 1988, 1989, 2000; De Castro, 2005a, 2005b; D e Castro \& Salamanca, 2007; De Castro, Cardona, Támara \& Gordillo, 2007). A sí, siempre está presente en toda decisión y proyecto del ser humano debido a que no hay seguridades absolutas en la vida que nos garanticen que vamos a ser siempre capaces de lograr 0 alcanzar aquello que tanto buscamos 0 anhelamos. De igual forma, tampoco hay certezas absolutas que garanticen que vamos a poder crear y desarrollar un proyecto de vida auténticamente, lo cual significa que siempre existe la posibilidad de que nuestro proyecto de vida falle o no sea muy apropiado para el desarrollo de nuestra potencialidad de ser. 0 aún más, existe siempre la posibilidad de descubrir que el proyecto vital que estamos desarrollando y las decisiones que estamos tomando ni siquiera alcancen a darnos o aproximarnos a un sentido de vida que nos haga sentirnos tan bien como deseamos o esperamos. Boss (1979) sintetiza esta idea cuando afirma que la existencia del ser humano hace frente al peligro cuando ésta enfrenta sus diversas posibilidades de ser.

Esta idea fue desarrollada en los resultados de una de las investigaciones acerca de la experiencia de ansiedad desarrolladas por D e C astro (2005a), a partir de las cuales se desarrollaron gran parte de las reflexiones teóricas de este artículo, la cual es expresada de la siguiente manera: 
Parece haber una fuerte relación entre la experiencia de estar ansioso y la confrontación de la incertidumbre que viene del futuro. A parentemente, la experiencia de ansiedad surge cuando los seres humanos sienten que existe la posibilidad de no ser capaz de alcanzar sus metas, de preservar aquello que les es significativo y/o de afirmar sus proyectos de vida. Entonces, podríamos decir que los seres humanos encuentran sentido en sus vidas cuando ellos son capaces de alcanzar esas metas 0 al poder afirmar sus proyectos de vida, lo cual los hace sentir como seresvaliosos en al gún sentido. A sí, la experiencia de ansiedad parece ser una reacción natural y siempre presente contra la posibilidad de no poder ser quien se quiere ser, lo cual es lo que nos hace sentir en gran parte que tenemosalgún valor como seres humanos. (p. 69)

A hora bien, en la psicopatología concretamente, la persona hace un inapropiado uso de su libertad para enfrentar la ansiedad, la cual sólo se convertirá en un síntoma patológico cuando evitemos confrontarla concientemente, lo cual hace que la asumamos destructiva o patológicamente. M ay (1996) comenta al respecto:

La ansiedad neurótica, por otro lado, es una reacción a una amenaza que es (1) desproporcionada al peligro objetivo; (2) involucra represión y otrasformas de conflicto intrapsíquico, y como corolario; (3) es manejada por medio de varias formas de reducción o supresión de la actividad y el conocimiento, tal como inhibiciones, desarrollo de síntomas, y una variedad de mecanismos neuróticos de defensa. ( $p .167$ )

$O$ tros psicólogoscomo Schneider (1990, 1995), basado en esta visión y entendimiento de $M$ ay acerca de la libertad y la ansiedad, comenta que tanto la angustia 0 ansiedad por sentir que el propio proyecto de vida está siendo o podría ser limitado o restringido, como la angustia 0 ansiedad producida por sentir temor ante el riesgo de tener que desarrollar o expandir el propio proyecto, generan sensaciones y comportamientos disfuncionales, extremistas y altamente psicopatológicos. A sí, cuando el ser humano teme ver limitada su libertad y bloqueado u obstaculizado en cuanto al desarroIlo de su potencial, puede desarrollar disfunciones hiperexpansivas, mediante las cuales pretendería negar toda posibilidad de restricción. A lgunos ejemplos de esto son la manía, la personalidad antisocial, la histeria, la personalidad narcisista, trastornos de impulsividad, claustrofobia y el abuso de sustancias estimulantes como la cocaína y sus derivados. Por otro lado, cuando el ser humano, por temor a perder algún tipo de seguridad (así sea aparente), teme apropiarse de su libertad y desarrollar y/o expandir su potencial a partir de la confrontación abierta con las distintas posibilidades del día y el riesgo e incertidumbre implicado en ellas, puede desarrollar disfunciones hiperconstrictivas, mediante las cuales pretendería negar toda nueva posibilidad de expansión o apertura hacia las distintas situaciones de la vida diaria. A Igunos ejemplos de esto son la depresión, el trastorno de ansiedad generalizada, dependencia, agorafobia, el trastorno obsesivo compulsivo, la personalidad paranoide y el abuso de sustancias depresoras como el alcohol. Finalmente, una combinación de estas dos formas de vivenciar la ansiedad, ante la restricción y la expansión del propio proyecto y potencial, podrían producir trastornos como la personalidad pasiva-agresiva, personalidad limítrofe, esquizofrenia y trastorno bipolar.

Esta concepción de Schneider respecto a las formas en que se puede vivenciar la ansiedad tiene la ventaja de que nos hace evidente la relación que existe entre la experiencia de ansiedad y el desarrollo del potencial de ser ante las distintas posibilidades y limitantes que se sienten y perciben en la vida cotidiana. En este mismo sentido, Riemann (1996) comenta que la ansiedad nos presenta dos antinomias, desde las cuales el ser humano desarrolla su proyecto de vida. En la primera antinomia, el ser humano se ve ante la paradójica exigencia de afirmar un valor como persona a través del mantenimiento de su forma de ser y/o individualidad, para convertirse en un individuo autónomo, a la vez que se pretende expandir a sí mismo a través de la apertura a las relaciones interpersonales para 
así, integrarse y adaptarse al mundo concreto en que se vive. La segunda antinomia viene dada a partir de la ansiedad que surge ante la necesidad de sentir que somos seres duraderos que viviremos al menos por al gún tiempo que nos permita entregarnos a desarrollar nuestros proyectos y alcanzar metas satisfactorias, al tiempo que sabemos que somos seres transitorios que no sabemos con seguridad cuánto tiempo más vamos a permanecer en este mundo.

A sí, la primera antinomia hace alusión al conflicto existencial entre la necesidad de alcanzar la individuación sin llegar a ser un individuo aislado. M ay (1990b) señala al respecto, que losindividuos tienen, por un lado, la necesidad de autoafirmarse a sí mismos para preservar algún valor que les otorgue sentido a sus existenciasy, simultáneamente, tienen la necesidad de salir de sí mismos para relacionarse con otros seres. Yalom (1984) afirma al respecto:

En primer lugar uno tiene que separarse del otro para llegar al aislamiento; tiene que estar solo para experimentar la soledad. Pero, es al confrontar la soledad cuando nos comprometemos con otros profunda y significativamente (...) si somos capaces de reconocer nuestra situación de aislamiento en la existencia y de confrontarla con resolución, también seremos capaces de acercarnos afectuosamente a otras personas. Si, por el contrario, estamos sobrecogidos por el temor ante el abismo de la soledad, en realidad no extendemos los brazos para acercarnos a otros, sino que los gol peamos para no ahogarnos en el mar de la existencia. (pp. 436-437)

La segunda antinomia hace alusión al dilema existente entre las necesidades y vivencias de finitud e infinitud. Este dilema nos evidencia que somos seres que en algún momento dejaremos de existir, pero que al mismo tiempo, estamos vivos. M ay et al. (1977), afirman que sólo tenemos dos verdades seguras: que en algún momento moriremos, pero que aún no estamos muertos. ¿Q ué haremos entre esas dos verdades? Es la pregunta más directa y clave que nos podemos hacer. Esta situación nos evidencia el conflicto existencial básico entre búsqueda y necesidad de libertad y búsqueda y necesidad de seguridad (Fromm, 1992; Yalom, 1984).

A partir de esta situación, podemos entender de mejor forma el planteamiento de M ay (1963, pp. 88-89) respecto a la forma cómo se produce la enfermedad mental en nuestro actual periodo sociohistórico. El autor nos muestra cómo la neurosis, más que ser un fracaso en la adaptación, es precisamente un intento desesperado y forzado por adaptarse: "la neurosis es precisamente el método que usa el individuo a fin de preservar su propio centro, su propia existencia (...), la neurosis esuna adaptación y ahí precisamente radica su mal"; y ese intento de ajuste forzoso es lo que se considera enfermizo en sí, ya que mediante este proceder el ser humano busca sentirse alguien ante un grupo determinado a la vez que con dicha adaptación pretende encubrir y no enfrentar sus propias carencias (como sus sentimientos de vaciedad o minusvalía, la necesidad de decidir por sí mismo, el asumir la soledad existencial, etc.).

A hora bien, no obstante que lo que en últimas se considera enfermizo es esa necesidad casi compulsiva de adaptarse, es pertinente aclarar que las consecuencias de este ajuste forzoso también son enfermizas, dado que la persona restringe su propio potencial creador, dejando así de desear por sí mismo, deja de actuar a voluntad y de asumir constructivamente su experiencia, lo cual implica que renuncia a su libertad y proyecto en el mundo, dejando como consecuencia que aparezcan entonces cualquier tipo de síntomas patológicos (objetivamente observables) como medio desesperado para taponar el vacío creado.

Este proceso a su vez denota la renuncia por el cuidado y desarrollo del ser, lo cual se entiende mejor si nos remitimos a la falta de deseo y de voluntad de creación y afirmación de estos deseos en la acción. Cuando el individuo evita esclarecer su existencia, simultáneamente está rechazando cualquier acto auténtico de desear orientado hacia el desarrollo y afirmación de las posibilidades de ser. El deseo queda reducido exclusivamente al mundo del $U$ mwelt, degenerando en un impulso 
ciego que se siente dentro de sí, desvinculado de la propia voluntad, sin posibilidad de poder integrarse a la experiencia creativa, y cuya única finalidad es exigir una descarga emocional inmediata quealivie el dolor y vacío que el hombre mismo ha creado al rechazarse. Es esto lo que en la actualidad se está observando con el cúmulo de actos compulsivos presentes en la cotidianidad del hombre, tales como las adicciones en todas sus formas (drogas, anorexia, bulimia, trabajo maniaco, el juego, el sexo, los deportes extremos y la búsqueda desenfrenada de sensaciones que pueden llegar a implicar la necesidad de sentir dolor físico).

En este sentido, la enfermedad es vista como la incapacidad para reconocer los propios deseos y sus significados (esto último se refiere a lo que gana u obtiene experiencialmente una persona al pretender afirmarse de alguna manera), así como la imposibilidad para reafirmar éstos en la acción por medio de la voluntad. Es decir, que, en palabras de May (1990a, p. 175), "no es el deseo lo que causa la enfermedad, sino que es la falta de deseo". Cuando el individuo prefiere restringir su potencial de desarrollo antes que verse relegado al ostracismo, está al mismo tiempo renunciando a desear por sí mismo cualquier acto que lo lleve a obrar consciente y comprometidamente con su propio devenir. A sí, cuando el individuo se impide a sí mismo desear, o lo que es lo mismo, orientar conscientemente sus deseos, estos aparecerán en la experiencia como separados o desarticulados de la propia intencionalidad o estructura psicológica concreta y exigirán una gratificación ciega y/o compulsiva, en la que el individuo no es capaz de sentir y captar en la experiencia el sentido de dicho deseo.

Todos estos aspectos están interrelacionados entre sí, de tal forma que no se deben entender linealmente, sino más bien comprenderlos como un proceso en que todos se influyen y relacionan simultáneamente unos con otros. La consecuencia de este proceso, es el no desarrollo de las potencialidades particulares del individuo, entendiendo éstas no como el desarrollo de capacidadesilimitadas que el individuo posee en distintas áreas y que aguardan por su puesta en marcha, sino más bien como la potencia o poder personal para enfrentar y dilucidar constructivamente la propia existencia a la vez que se afirman los valores que se encaminan a desarrollar el ser.

D e esta forma, cuando el individuo se evade de descubrir sus deseos y orientarlos conscientemente, no desarrolla su potencial y debe recurrir a medios evasivos que compensen de alguna forma el vacío creado. Estos medios evasivos están marcados por un afán por tratar de olvidarse de la existencia concreta que se debe asumir, lo cual provoca, a su vez, un sinfín de trastornos y de síntomas neuróticos que son a la vez producto y consecuencia de este enmascaramiento de la existencia. A sí vista, la enfermedad es un modo ineficaz y desesperado por evitar la angustia resultante de la confrontación con los supuestos básicos de la existencia tales como la libertad, voluntad, responsabilidad, el sentido, la muerte y el aislamiento existencial (Yalom, 1984); es un intento por enmascarase a sí mismo tanto la responsabilidad de descubrir los propios deseos y los significados que se buscan al afirmar o evitar dichos deseos, como el asumir una actitud autónoma y consciente ante estos.

Según Yalom (1984, p. 13) el punto básico por resaltar aquí es que "la posición existencial hace hincapié en un tipo diferente de conflicto básico (...) que emana del enfrentamiento del individuo con los supuestos básicos de la existencia. Y con la expresión 'supuestos básicos' me refiero a ciertas preocupaciones esenciales, a ciertas propiedades intrínsecas queineludiblemente forman parte de la existencia del ser humano en el mundo". Es decir, que es a partir dela confrontación y relación del individuo con su existencia y sus condiciones de vida, que el ser humano tiene la posibilidad de desarroIlar su potencial y proyecto vital auténticamente y en caso de fracasar éstey ver frustrada su necesidad de reafirmarse como persona, es probable que en esos momentos, si no asume constructivamente dicha experiencia, surjan dependiendo de lo que la persona busque, de sus características particulares de ser y a la estructura de su existencia, síntomas patológicos con los que él mismo pretenda recobrar la seguridad perdida y que por sí mismo (auténticamente) no logró. En otras palabras, mientras más 
se represe o restrinja el sentido del ser (el potencial de valorar constructivamente), mayor será la sensación de insignificancia y el precio que se paga por esto es la neurosis y las sen saciones implicadas en ella, como son la apatía, dependencia, obsesividad, compulsividad, rigidez, dogmatismo, fallas en la expresión de sí mismo y en la comunicación, etc. (James H annush, 1999).

En este sentido, si atendemos a la enfermedad mental a partir del cuestionamiento por el ser, desu proyecto en el mundo y de la estructura de su existencia, ya nos estamos relacionando con "alguien", precisamente con quien crea la enfermedad de acuerdo con sus propiasnecesidades existenciales, y no sólo con un mero impulso o mecanismo psíquico en abstracto. Rompemos así la barrera que nos impide compren der "quien está detrás" y sirviendo de base o soporte a la enfermedad, captando entonces el sentido que dicha persona pretende darle a sus síntomas, lo cual nos permite llegar directamente tanto al centro del problema mismo como a la estructura particular de potencialidades que se ha visto frustrada. Y, obviamente, esto facilita movilizar a la persona hacia el desarrollo de su real proyecto y reafirmación como ser-en-el-mundo, ya que sólo cuan do la persona logre reafirmarse auténticamentea sí misma en el mundo, podrá comenzar a superar su enfermedad. Sobre este punto, M ay et al. (1977) comentan:

La función del psicoterapeuta no consiste en "curar" los síntomas neuróticos del paciente, aunque este es el motivo que induce a la mayoría de la gente a acudir a terapia. En realidad, el hecho de que éste sea su motivo, refleja su problema. Pero la psicoterapia se ocupa de al go más fundamental, que es ayudar a la persona a que experimente su existencia como real; cualquier curación de los síntomas que esté llamada a durar debe ser un subproducto de esto. (p. 116)

Lo anterior se refiere, ahora más concretamente, a aquello que comentábamos al principio del artículo cuando hablábamos de que los constructos teóricos y la técnica en sí deberían tener sentido a partir y en función de la persona existente (Van
D eurzen, 1988, 1997; Keen, 2000; M oustakas, 1994). Según la psicología existencial, entonces, antes de que le demos poder o autonomía por sí mismos a los mecanismos, impulsos y estructuras psíquicas teóricamente entendidas, debemos entender que todos éstos son creadosy/o mantenidos por una persona específica con una intencionalidad y finalidad muy puntual. Binswanger (1997, p. 251) aclara mucho este panorama cuando nos dice: "nosotros (los psicoterapeutas existenciales) no nos detenemos como el biólogo o el psicopatólogo en el hecho particular, en el síntoma aislado, sino que nos lanzamos en busca de un todo orgánico dentro del cual pueda comprenderse ese hecho particular como un fenómeno parcial. Pero este todo lo es (...) en el sentido de la unidad de un diseño del mundo".

Finalmente, y como conclusión, recordemos que para poder comprender la psicopatología apropiadamente, tengamos siempre presente que no hay experiencia y creación humana desligada de la total orientación de la persona en el mundo y de aquel valor y/o significado que ésta pretenda reafirmar o preservar. Si esto no fuera cierto, estaríamos en capacidad de responder al siguiente cuestionamiento: ¿cómo pueden existir (por poner unos ejemplos), la ansiedad, el inconsciente, los procesos de pensamiento o los mecanismos de defensa, sin alguien que esté ansioso, que haga inconsciente la experiencia, que realice los procesos de pensamiento o que cree los mecanismos defensivos? Todo pensamiento, impulso, deseo, síntoma, mecanismo psíquico o conducta, siempre presenta una intencionalidad que apunta a un significado concreto. ¿Q uién crea o pretende crear y/o preservar dicho significado y con qué fin? Ese es precisamente el punto de partida de toda comprensión psicológica.

\section{Referencias}

A sociación A mericana de Psiquiatría. (1996). M anual de diagnóstico y estadístico de los trastornos mentales DSM IV [Versión electrónica]. Barcelona: M asson, S.A . 
Binswanger, L. (1977). La escuela de pensamiento de A nálisisExistencial. En R. M ay, E. A ngel \& Ellenberger, $H$. (Eds.), Existencia, una nueva dimensión en psiquiatría y psicología (pp. 235-261). M adrid: Gredos.

Binswanger, L. (1988). Tres formas de la existencia frustrada. Buenos A ires: A morrortu.

Blankenburg, W. (1980). Phenomenology and psychopathology. Journal of Phenomenological Psychology, 11, 50-69.

Boss, M . (1979). Existential foundations of medicine and psychology. N ew York: Jason A ronson.

Boss, M . (1982). Psychoanalysis and D aseinanalysis. N ew York: D aC apo Press.

Boss, M . (Ed.). (2001). Zollikon Seminars. Evanston, IL: N orthwestern U niversity Press.

Bugental, J. (1964). Five basic postulates of humanistic psychology. Journal of $\mathrm{H}$ umanistic Psychology, 1(41), 2001.

Bugental, J. (1987). T he art of the psychotherapist. N ew York: W. W. N orton and Company.

Bugental, J. (1997). T he search for authenticity: A n existential analytical approach to psychotherapy. $\mathrm{N} \mathrm{ew}$ York: Irvington Publishers.

De Castro, A . (2000). La Psicologia Existencial de Rollo $M$ ay. Barranquilla, Colombia: U ninorte.

De Castro, A . (2005a). Comprensión cualitativa de la experiencia de ansiedad. SU M A Psicológica, 12(1), 61-76.

De Castro, A . (2005b). A hermeneutical understanding of the experience of being anxious. $Q$ ualitative Research in Psychology, 2(2), 141-167.

De Castro, A .\& Salamanca, M . (2007). Comprensión de la experiencia de ansiedad a la luz de la perspectiva de salud mental del psicoanálisis existencial. Psicología desde el C aribe, 20, 156-187.

De Castro, A ., Cardona, E., Gordillo, M ., \& Támara, S. (2007). Comprensión de la experiencia de ansiedad en un estudiante que pertenece a un grupo artístico de la Universidad del N orte de la ciudad de Barranquilla. Psicología desde el $\mathrm{C}$ aribe, $19,49-80$.

De Carvalho, R. (1992). The humanistic ethic of Rollo M ay. Journal of $H$ umanistic Psychology, 32, 7-18.

Diamond, S. (1996). A nger, M adness, and the D aimonic. $\mathrm{N}$ ew York: State $\mathrm{U}$ niversity of $\mathrm{N}$ ew York.
D orr, O . (1995). A ntropología Psiquiátrica. Santiago de Chile: U niversitaria.

D reyfus, H . (1996). Ser-en-el-mundo. Santiago deC hile: Cuatro Vientos.

Ferro Bayona, J. (2001). Filosofía y psicología en el análisis existencial de Ludwig Binswanger. Psicología desde el $C$ aribe, 7, 47-59.

Fischer, W. (1986). O $\mathrm{n}$ the phenomenological approach to psychopathology. Journal of Phenomenological Psychology, 17, 65-76.

Fischer, W. (1988). Theories of anxiety. Lanham, U.S.A : $U$ niversity Press of A merica.

Fischer, W. (1989). A n empirical-phenomenological investigation of being anxious. En R. Valle \& $S$. $\mathrm{H}$ alling (Eds.), Existential phenomenological perspectives in psychology (pp. 127-163). N ew York: Plenum Press.

Fischer, W. (2000). The psychology of anxiety: A phenomenological description. The $\mathrm{H}$ umanistic Psychologist, 28, 153-166.

Fromm, E. (1992). La patologia de la normalidad. Barcelona: Paidós

Fromm, E. (1994). El miedo a la libertad. Barcelona: Paidós.

H alling, S. \& Goldfarb, M . (1996). The new generation of diagnostic manuals (DSM III, DSM III R, and DSM IV): A n overview and a phenomenologically based critique. Journal of Phenomenological Psychology, 27, 49-71.

James $H$ annush, M . (1999). The development of the self in the light of the existential-humanistic psychology of Rollo M ay. En Keith Hoeller (Ed.), Rollo $M$ ay's existential psychology. Review of Existential Psychology and Psychiatry, 1, 2, 3(24). E dición Especial.

Keen, E. (1970). T hree faces of being: Toward a clinical existential psychology. $\mathrm{N}$ ew York: A ppleton Century Crofts.

Keen, E. (2000). U Itimacy and triviality in psychotherapy. Westpart, USA : Praeger Publisher.

Laing, R. (1974). Inseguridad ontológica. En Theodore M illon (Ed.), Psicopatologia y personalidad (pp. 207 - 217). M éxico: N ueva Editorial Interamericana.

M alone, $K$., M alone, D., M alone, P. \& M alone, T. (1995). Psychopathology as non-experience. En 
Keith Holler (Ed.), Review of Existential Psychology and Psychiatry, 22, 84-98.

May, R. (1963).Psicología Existencial. Buenos A ires: Gedisa.

May, R. (1990a). La psicología y el dilema del hombre. M éxico: Gedisa.

May, R. (1990b). O $n$ the phenomenological bases of therapy. Review of Existential Psychiatry and Psychology, 1-3(20), $49-61$.

M ay, R. (1996). T he meaning of anxiety. N ew York: The Ronald Press Company.

May, R., A ngel, E. \& Ellenberger, H. (1977). Existencia, una nueva dimensión en psiquiatría y psicología. $M$ adrid: Gredos.

M erleau Ponty, M . (1962). Phenomenology of perception. $N$ ew York: Routledge.

M oustakas. C. (1994). Existential psychotherapy and the interpretation of dreams. $\mathrm{N}$ ew Jersey: Jason A ronson.

Pollio, H ., H enley, T. \& Thompson, C. (1997). Thephenomenology of everyday life. $N$ ew York: Cambridge U niversity Press.

Riemann, F. (1996). Formas básicas de la angustia. Barcelona: H erder.
Schneider, K. (1990). The paradoxical self: Toward an understanding of our contradictory nature. $\mathrm{N}$ ew York: Plenum.

Schneider, K . \& M ay, R. (1995). T he psychology of existence. $\mathrm{N}$ ew York: $\mathrm{M}$ cG raw-Hill.

Smith, M . \& Jones, E. (1993). N eophobia, ontological insecurity and existential choice following trauma. Journal of H umanistic Psychology, 4(33), 89-109.

Spinelli, E. (2000). T he interpreted world: A n introduction to phenomenological psychology ( $7^{\mathrm{a}} \mathrm{ed}$.). London: Sage Publications.

Van den Berg, J. (1997). A different existence (17a ed.). Pittsburgh: D uquesne U niversity Press.

Van D eurzen, E. (1997). Everyday mysteries: Existential dimensions of psychotherapy. London: R outledge.

Van D eurzen, E. (1988). Existential counseling in practice. London: Sage Publications.

Yalom, I. (1984). Psicoterapia existencial. Barcelona: $\mathrm{H}$ erder.

Yalom, I . (1995). El día queN ietzschelloró. Buenos A ires: Emecé Editores.

Yalom, I. (2000). Psicoterapia Existencial y Terapia de $G$ rupo. Barcelona: Paidós.

Yalom, I. (2002). The G ift of Therapy. N ew Cork: Perennial Publishers. 